\title{
Cataract Surgery Barrier Model: A framework for intervention of cataract blindness in Malaysia
}

\author{
Abdul Mutalib', Nurulain Mat Zin², Ahmad Shahir ${ }^{3}$, Asma Hassan'1
}

${ }^{1}$ Faculty of Medicine, Universiti Sultan Zainal Abidin, 20400 Kuala Terengganu, Terengganu, Malaysia

2 Department of Ophthalmology, Hospital Kuala Krai, 18000, Kuala Krai, Kelantan, Malaysia

3 Department of Occupational Therapy, Faculty of Health Sciences, Universiti Teknologi MARA, 42300 Puncak Alam, Selangor, Malaysia

abdulmutalib@unisza.edu.my, safain84@gmail.com, shahirmutalib@gmail.com, asmahassan@unisza.edu.my

\begin{abstract}
Surgery can easily cure and prevent blindness due to cataract. However, cataract still poses a major public health problem as the single most common cause of global blindness. Identifying the barriers to access cataract surgery is essential to effectively address this problem. By utilising the interpretative phenomenological analysis approach in this study, we identified barriers at the personal, primary care and specialist care level. Based on these findings, a model is designed to better understand and improve the strategy to address the barriers to improve the uptake of cataract surgery in order to prevent cataract blindness in Malaysia.

Keywords: Cataract blindness; Cataract surgery; Health care model; Interpretative phenomenological analysis

eISSN 2514-7528 @ 2019. The Authors. Published for AMER ABRA cE-Bs by e-International Publishing House, Ltd., UK. This is an open-access article under the CC BY-NC-ND license (http://creativecommons.org/licenses/bync-nd/4.0/). Peer-review under responsibility of AMER (Association of Malaysian Environment-Behaviour Researchers), ABRA (Association of Behavioural Researchers on Asians) and cE-Bs (Centre for EnvironmentBehaviour Studies), Faculty of Architecture, Planning \& Surveying, Universiti Teknologi MARA, Malaysia. DOI: https://doi.org/10.21834/jabs.v4i13.330
\end{abstract}




\subsection{Introduction}

Cataract is due to the progressive formation of opacity within the crystalline lens of the eye, which obstructs one's vision and eventually leads to blindness. According to the World Health Organisation (WHO), blindness is defined as the situation when the best corrected visual acuity of a person is worse than $3 / 60$ in the better eye (WHO, 2007). Blindness is a serious public health problem, therefore, the prevention of blindness program constitutes one of the WHO's main agenda worldwide. Early cataract detection and surgery are imperative for restoring normal vision. However, despite the ease and availability of cataract surgical services, cataract remains as the single most common cause of global blindness that poses $81 \%$ risk of affecting older people worldwide (Bourne, Flaxman, Braithwaite, et al., 2017).

In Malaysia, Salowi (2014) revealed that cataract is the most common cause of visual impairment and blindness among individuals aged 50 and above. This finding suggests the possibility of poor utilisation of eye care and cataract surgery services as the main phenomenon that causes the existence of cataract blindness in Malaysia. The presence of such circumstances in Malaysia is indeed surprising, considering the widespread availability of ophthalmology services in all major hospitals throughout the country. It is unknown as to what are the major barriers that contribute to this phenomenon. Intuitively, the identification of such barriers could serve as the basis for developing a method to improve the effectiveness of the eye care service provision, alongside the effort to increase the uptake of cataract surgery to prevent blindness.

Therefore, this study aims to identify and characterises the barriers that lead to the delay in cataract surgery uptake in Malaysia by investigating how patients with cataract made sense of their lived experiences endured throughout the state of visual deterioration until severe blindness. The findings from this study could improve our understanding of how to implement a more comprehensive eye care services, and timely uptake of cataract surgery, so as to prevent blindness due to cataract in Malaysia.

\subsection{Literature Review}

In order to formulate a strategy to improve the uptake of cataract surgery, it is imperative to first understand and characterise the barriers that impede the utilisation of eye care services and uptake of cataract surgery. Currently, the universally accepted framework of health care models cover all health conditions from the various angles with a limited perspective on the aspect of surgical care barriers (Irfan et al., 2012; Mclntyre, Thiede \& Birch, 2009). The provision of health care services has been described in five general dimensions related to the availability, accessibility, affordability, adequacy, and acceptability (Obrist, Iteba, Lengeler, et al. 2007).

The Health Belief model, such as the Theory of Reasoned Action, the Theory of Planned Behaviour, and the Andersen's model of Health Services Utilisation, have characterised the health care seeking behaviour within a general perspective (Andersen, 2008). In order to make it more specific, Andersen introduced the Andersen's behavioural model which highlighted the effect of needs, predisposing conditions, and enabling factors on the general provision of health care services for the population. However, the frameworks of these health 
models are still broad, and lack focus on explicitly defining, explaining, and suggesting the methods for addressing the barriers that impede the access to cataract surgery services.

Carrillo et al. (2009) then proposed the Health Care Access Barriers (HCAB) model which implicates three types of barriers to access health care, which are decreased screening, late presentation to care, and lack of treatment, as the main reason for most poor health outcomes and health disparities. However, the HCAB is not a comprehensive model that includes all determinants. Subsequently, Irfan et al. (2012) has comprehensively reviewed and described the barriers to access surgical care system which include deficiencies in the capacity of infrastructure, human and physical resources, organisation and monitoring, and other barriers such as lack in knowledge and skills due to inadequate educational opportunities, deficient communication, and delayed referral among many other factors.

The utilisation of the surgical care services in their proposed Health Care Barrier model explicitly describes the influence of the peoples' attitudes, their beliefs of diseases, social structure, and population demographics (Irfan et al., 2012). Identifying the whole spectrum of the measurable and modifiable factors of the recognisable barriers to the cataract surgical services need to be distinctly targeted. These information could facilitate root-cause analysis and contribute to the formulation of a better strategic framework for planning the most appropriate and timely cataract surgery intervention programs.

Many countries, except Malaysia, have already extensively studied the barriers to cataract surgery for many years and have observed changes in the trend. For instance, earlier studies in India have revealed factors such as need not felt, poverty, and poor transportation as the major barriers, whereas cost, accessibility, and lack of awareness, were barriers more significantly related to in the rural population (Vaidyanathan et al., 1999; Kovai et al., 2007). The outcomes of these studies motivated our present study, which explored and defined the characteristics and level of barriers to cataract detection, care process and particularly cataract surgery affecting the elderly population in the eastern zone of Peninsular Malaysia. Based on the output of this study, we proposed a 'Cataract Surgery Barrier' model developed specifically for the current situation in Malaysia.

\subsection{Methodology}

This study employed the interpretative phenomenological analysis (IPA), a qualitative approach more renowned in health psychology research, in order to understand and explore how patients with cataract made sense of their lived experiences endured throughout the state of progressive blurring of vision until blindness. Participants were identified within the eastern zone of Peninsular Malaysia which includes the states of Pahang, Kelantan, and Terengganu. Qualified optometrists directly involved in the preliminary investigation and preparing patients for cataract surgery identified participants who are in the state of severe blindness in both eyes due to cataract for this study. The inclusion criteria include individuals confirmed to have cataract with the best corrected visual acuity worse than $3 / 60$, could speak fluent Malay, and aged above 50 years old. Subjects who exhibit any associated ocular or systemic co-morbidity and speech difficulties were excluded from the in-depth face-to-face interview. The summary of the eleven participants is as listed in Table I. 
Table 1: Characteristic of study participants identified by abbreviated names

\begin{tabular}{|c|c|c|c|c|c|c|c|c|}
\hline \multirow[t]{2}{*}{ No. } & \multirow[t]{2}{*}{ Abbr. } & \multirow[t]{2}{*}{ Gender } & \multirow[t]{2}{*}{ Age } & \multicolumn{2}{|c|}{ Visual acuity } & \multirow{2}{*}{$\begin{array}{l}\text { Marital } \\
\text { status }\end{array}$} & \multirow[t]{2}{*}{ Location } & \multirow{2}{*}{$\begin{array}{l}\text { Socio-economic } \\
\text { status }\end{array}$} \\
\hline & & & & Right & Left & & & \\
\hline 1. & $\mathrm{YH}$ & $F$ & 59 & $\mathrm{CF}$ & $\mathrm{CF}$ & Married & $\begin{array}{l}\text { Besut, } \\
\text { Terengganu }\end{array}$ & $\begin{array}{l}\text { Good. Own house, } \\
\text { car and land }\end{array}$ \\
\hline 2. & IM & M & 54 & $\mathrm{CF}$ & $\mathrm{CF}$ & Married & $\begin{array}{l}\text { Besut, } \\
\text { Terengganu }\end{array}$ & $\begin{array}{l}\text { Very poor. Stays in } \\
\text { surrogate house }\end{array}$ \\
\hline 3. & TA & $F$ & 72 & $\mathrm{HM}$ & PL & Widow & $\begin{array}{l}\text { Kok Lanas, } \\
\text { Kelantan }\end{array}$ & $\begin{array}{l}\text { Good. Lives with } \\
\text { her child }\end{array}$ \\
\hline 4. & $\mathrm{RB}$ & $\mathrm{F}$ & 51 & $\mathrm{CF}$ & $2 / 60$ & Divorcee & $\begin{array}{l}\text { Tumpat, } \\
\text { Kelantan }\end{array}$ & $\begin{array}{l}\text { Moderate. Lives } \\
\text { with her daughter }\end{array}$ \\
\hline 5. & $\mathrm{FL}$ & $F$ & 72 & $\mathrm{CF}$ & $\mathrm{CF}$ & Widow & $\begin{array}{l}\text { Temangan, } \\
\text { Kelantan }\end{array}$ & $\begin{array}{l}\text { Good. Living in her } \\
\text { own house with son }\end{array}$ \\
\hline 6. & AN & $F$ & 51 & $\mathrm{CF}$ & $\mathrm{CF}$ & Married & $\begin{array}{l}\text { Kuala Krai, } \\
\text { Kelantan }\end{array}$ & $\begin{array}{l}\text { Poor. Husband has } \\
\text { no fixed income }\end{array}$ \\
\hline 7. & JP & $F$ & 72 & $\mathrm{HM}$ & $2 / 60$ & Widow & $\begin{array}{l}\text { Kuala Krai, } \\
\text { Kelantan }\end{array}$ & $\begin{array}{l}\text { Moderate. Depends } \\
\text { on DSW stipends }\end{array}$ \\
\hline 8. & $\mathrm{HZ}$ & M & 81 & $1 / 60$ & $2 / 60$ & Married & $\begin{array}{l}\text { Bukit lbam, } \\
\text { Pahang }\end{array}$ & $\begin{array}{l}\text { Good. Has two } \\
\text { houses }\end{array}$ \\
\hline 9. & TC & $\mathrm{F}$ & 70 & $1 / 60$ & $\mathrm{HM}$ & Widow & $\begin{array}{l}\text { Rompin, } \\
\text { Pahang }\end{array}$ & $\begin{array}{l}\text { Moderate. Stays } \\
\text { with her daughter }\end{array}$ \\
\hline 10. & KT & $F$ & 73 & PL & $\mathrm{HM}$ & Widow & $\begin{array}{l}\text { Kemaman, } \\
\text { Terengganu }\end{array}$ & $\begin{array}{l}\text { Good. Stays with } \\
\text { her daughter }\end{array}$ \\
\hline 11. & HS & $F$ & 63 & $\mathrm{PL}$ & $\mathrm{HM}$ & Widow & $\begin{array}{l}\text { Kemaman, } \\
\text { Terengganu }\end{array}$ & $\begin{array}{l}\text { Good. Stays with } \\
\text { daughter }\end{array}$ \\
\hline
\end{tabular}

(Legend: Abbr.: Abbreviation, F: Female, M: Male, CF: Counting fingers, HM: Hand movement, PL: Perception of light, DSW: Department of Social Welfare)

The protocol of this study was approved by the Human Research Ethics Committee of the Universiti Sultan Zainal Abidin, Kuala Terengganu (Ref no.: UniSZA.C/1/UHREC/6281(64) dated 2nd May 2016). Before the interview, participants gave their consent, with or without the presence of immediate family members for the step-by-step and standardised interview protocol with an in-depth approach following the recommendation of PlummerD'Amato (2008). All participants granted the use of a digital audio recorder to record the interview sessions. All interview sessions were performed according to a standardised interview format improved during the pilot study. The conduct of the interview in the participants' own homes, as well as in their native language or dialect, have particularly encouraged and facilitated the ease of the interview. Furthermore, these two factors have also maintained the originality of the perspective of our participants in highlighting their consideration for cataract surgery by any well-recalled or important events.

The interview session was initiated by asking the participants to describe their lived experience throughout the stage of progressive blurring of vision until blindness. This question instinctively led them to describe why they were previously unwilling to undergo cataract surgery has brought patients to the negative side of the situation. Patients narrated their experiences on why, where, when and what was considered as phenomenological life 
events that were related to their poor sight. This information was important to justify the reasons behind why they have allowed themselves to become blind. Besides their verbal responses, their non-verbal expressions such as their appearance, smiling, sitting posture, eye movement, eye fixation, bodily act and coordination, which are important for interpreting their detailed verbal responses, were observed and recorded. Their home infrastructure and environment, personal activities, involvement, and bonding with their family members were also observed to better understand participants' narration.

All audio recordings were transcribed verbatim according to their original language. Two independent researchers analysed the transcriptions according to the six stages of the IPA approach designed by Smith, Flowers and Larkin (2009). This IPA approach allows for a deep understanding of the significance and unexpected things which happen to the participants during their state of visual deterioration, as they actively engage in making sense of their lived situations (Smith, 2016). The analytical procedure of the participants' transcription was commenced with data familiarisation and immersion before the validation process of its theoretical annotations and concluded by matching and verification of the situational analysis. The connections between the listed initial themes and quotes were verified for each participant.

The identified quotes were coded to facilitate later recognition using the NVivo software version 8.0. Adherence to the similar process of analysis guaranteed equal chances of identifying the same or a new theme in every transcript. At least two independent researchers checked and verified every theme and resolved any conflict during the analysis process. The recruitment of additional participant was ended when analysis could not identify any additional new theme, which indicates attaining data saturation. All the identified themes were then classified, merged and categorised into main themes and subthemes, organised according to the research objectives. The original quotes and themes in the Malay language were maintained throughout the whole IPA process of verbatim transcription, analysis and identification of theme - without translating into English until the final stage of this manuscript preparation.

\subsection{Results}

The utilisation of the IPA approach initially identified almost sixty factors or themes before merging, classifying and further merging them into the final 15 subthemes. These final subthemes were classified under three main themes, each directly related to levels of barriers according to the Malaysian system of health care provision, which are the (1) personal, (2) primary care, and (3) specialist care levels. The identified subthemes are regarded as the participants' perception as their major hindrance to undertake cataract surgery, which happens in line with the progression of their visual loss in the order consistent with the standard eye care service provision.

The subthemes identified as barriers at the personal level are issues regarding their perceived need for sight, activities of daily living (ADL), apprehension, poor physical status, poor family support and financial adversity. Barriers noted at primary care level, occurred even in the convenience of regular visits to the primary care providers, are nondisclosure of 
their visual problems due to belated needs for better sight, delayed awareness of visual status, social stigma, and problems related to patient-provider-related issues such as miscommunication and delayed referral. Barriers at the specialist care level, i.e. the final level of care for cataract surgery, are accessibility, administrative bureaucracy, waiting time for surgery and cost related to cataract surgery.

\subsection{Personal level barrier}

Barriers identified at the personal level (main themes) are related to the factors (subthemes) which prevent patients to present themselves or disclose their visual problems to the primary health care clinic or providers. The subthemes and the corresponding quote of the participants with their visual acuity status are given below.

\section{Perceived need for sight}

"I did not notice any problem with my sight until lately. Only one eye had a poor vision, but I was still strong and can continue to work as a gardener". [Madam KT: Visual acuity (of the right and left eye, respectively) - PL (perception of light) \& HM (hand movement), Terengganu]

\section{Activities of daily living}

"My 40-year-old son was involved in a motor vehicle mishap when he was 23. He can only sit and crawl to the toilet. I have to switch on the TV for him. I need to feed and bath him. I have been looking after him since then, and there is no one else available to help me". [Madam JP: Visual acuity (VA) - HM \& 2/60, Kelantan]

\section{Apprehension}

"Some of my relatives advised me against doing the eye surgery. They said my vision could get worse and I might die during the surgery". [Madam FL: VA - CF (counting fingers) in both eyes, Kelantan]

\section{Poor physical status}

"I cannot walk because both my legs hurt very much and I cannot move at times. I have gone for a medical check-up, but the doctor could not determine the problem. I do not think I am fit for surgery in this condition". [Mr HZ: VA - 1/60 \& 2/60, Pahang]

Poor family support

"I am still undecided on eye surgery. I have no one to care for me during the surgery, and I might create much inconvenience to others". [Madam AN: VA - CF in both eyes, Kelantan]

Financial adversity

"We are from an impoverished family as my husband can only work for a few days. He still cannot find any job (sobbing) for the last few months. We do not have enough to eat, how can we afford eye surgery?". [Madam AN: VA - CF in both eyes, Kelantan] 


\subsection{Primary care level barrier}

Barriers at the primary care level are issues which led to the delayed disclosure, confirmation of diagnosis and referral by the primary care practitioners to the next level of care by the specialist. The subthemes and corresponding quotes of the participants with their visual acuity status are listed below.

Belated needs for better sight

"I went to the health clinic quite often, but (I do not mind about my poor vision as long as) I am capable of using the rice cooker to prepare the rice. If I need to use the gas stove, I will ask my grandchild to tell me when it is done". [Madam TC: VA - 1/60, HM, Pahang]

Delayed awareness of visual status

"I visited the nearby health clinic regularly for my check-up and medications. I do realise that my vision is blurred, but I am not sure the reason. I never tell the doctor about my vision. Can they check my eyes too?". [Madam HS: VA - PL \& HM, Terengganu]

Social stigma

"I am not sure why I do not want anybody to know about my poor vision (smiling). Maybe because I do not want them to worry about my condition. I want to keep it a secret, but they have realised about it themselves". [Madam TA: VA - HM, PL, Kelantan]

Miscommunication

"I informed the doctor about my poor vision during my visits for blood pressure medications, but the doctor did not do anything about it. The same thing happened even when my daughter came with me and told the doctor again about my sight. Again the doctor did not take any action. Only when my vision became much worse, the doctor noted it and referred me to the specialist. By then my right eye could barely see, and I had to depend on my left eye". [Madam JP: VA - HM \& 2/60, Kelantan]

Delayed referral

"I told the doctor about my poor vision in 2015 (i.e. two years ago). The doctor checked my eyes and told me to see the eye specialist. However, the staff nurse in charge went for a course and no one else replace her until recently". [Madam HS: VA - PL \& HM, Terengganu]

\subsection{Specialist care level barrier}

Barriers at the specialist care level occur even when the diagnosis of cataract has been confirmed, and the patient has agreed to undertake cataract surgery. The issues are regarding the difficulties which have led to the delay in the performance of cataract surgery. The subthemes and the corresponding quote of the participants with his or her visual acuity status are given below.

\section{Accessibility}

"I am staying in Maran which is quite near to the district hospital where I saw the specialist, 
but it is too far for me to travel to Hospital Temerloh for the cataract surgery". [Madam RB: VA - CF \& 2/60, Pahang]

Administrative bureaucracy

"Since I had diabetes mellitus, I visited the eye specialist regularly for eye screening once a year, even when my sight was still pretty good at that time. Now my sight is getting worse, but I could not go because I lost my appointment card in the big flood (two years ago)". [Madam FL: VA - CF both eyes, Kelantan]

\section{Waiting time for surgery}

"I went to see the eye specialist in June. I thought I could have the cataract surgery done immediately, but I was told to wait because the vacancy is only available in September. Now it is already October, but the hospital still has not called me for the surgery yet". [Madam KT: VA - PL \& HM, Terengganu]

Cost related to cataract surgery

"I cannot get anyone to help me. I have requested the Social Welfare Department for some assistance, but my application was rejected because I am too young. I have only five hundred ringgit that I have been saving for the surgery". [Madam RB: VA - CF \& 2/60, Kelantan]

\subsection{Discussion}

The IPA approach employed in this study has successfully recognised the initial barriers to cataract surgery at the personal level by factors hindering patients to present themselves to the primary care providers. The current Malaysian health system requires all patients to obtain the initial care by 'walk-in' to the primary care providers for consultation and diagnosis of all their ailments including poor vision due to cataract. This step is necessary for the initial treatment or referral to see the ophthalmologist for the subsequent specialist care. The barriers at this level reflect the patients' attitude in accepting and adapting their visual loss as a natural phenomenon of ageing, resulted by their unawareness about cataract which prevented them from presenting and disclosing their visual problems.

Like most Malays in Malaysia, our study participants are fully committed to maintain the needs of their family members and are very cautious about matters that might interrupt their daily routine and ADL (Mutalib et al., 2016) such as their physical status before, during and after the intended cataract surgery. They were very apprehensive by the thoughts of negative outcomes of cataract surgery, and its effect on the care and livelihood of their family members, and the implication of cost incurred for surgery. This is because their sense of purpose and quality of life had always been about by their continuous engagement with their family members, their occupational activities and ADL (Ibrahim \& Dahlan, 2015). Their decisions were significantly affected by the amount of moral and physical support they provide and acquire from their family members and were proven to be the essential components for their wellbeing and quality of life (Aisyah et al., 2016). These could be the reasons for their reluctance to disclose their initial visual problem to any family members or 
primary care providers.

Most primary care clinics in Malaysia are conveniently located and regularly visited for common ailments and chronic medical conditions such as diabetes mellitus, hypertension and asthma. However, many patients tend to keep their visual problem to themselves because of the anticipated need for special attention and the social stigma. Earlier study have noted similar attitude among most of their elderly patients as they were more likely to attend treatment in primary care clinic for common disorders such as diabetes mellitus (92\%), hypertension (90\%), joint pain (54\%) and dental problems (47\%), in considerable contrast to the rather more insidious conditions such as visual problem (20\%) and memory impairment (13\%) (Mahesh et al., 2013).

Miscommunication is also regarded by some of our participants as one of the major barriers. This could be due to ignorance of doctors at the primary care level concerning cataract and its surgical treatment. The breakdown in communication fails to alleviate patients' refusal to voluntarily disclose their poor visual status. This situation is made worse by their ignorance or failure to act upon the patients' visual complaint, which has led to the delay in diagnosis and referral needed for the subsequent specialist care and surgery.

In general, the barriers at primary care level represent the reasons for the delay in detection of impaired vision, late diagnosis of cataract, slow process of care for the timely uptake of cataract surgery, thereby allowing adequate time for the cataract to progress until the stage of severe blindness. This is consistent with the previous study findings which identified barriers associated with attitude, referral processes and eye care provision (Dhaliwal \& Gupta, 2007; Irfan et al., 2012). Promoting awareness about cataract among individuals, community and health care providers, by taking advantage of their relationship and interdependence with their family and community members, was advocated by Nurulain et al. (2018) as an approach to ensure early presentation and detection.

Routine opportunistic screening of visual acuity status during every visit at all primary and secondary health care facilities in the country was also recommended for patients above 50 years old to ensure early detection of cataract (Nurulain et al., 2018). The opportunistic vision screening measure is worth implemented as the national prevalence of impaired vision was $5.5 \%$, ranging from $4.6 \%$ to $9.4 \%$ throughout Malaysia (Chew et al., 2018).

As the specialist is responsible for the final level of care including cataract surgery, issues such as administrative bureaucracy, accessibility, waiting time and cost of surgery are the main issues identified as barriers at this level. Outreach program is one way of addressing the major barriers at primary and specialist care level simultaneously among the rural population in Malaysia. Since 2013, the total number of cataract surgery done during the outreach visits had increased from 140 to 1704 in 2015, with half of the eyes operated (49.3\% in 2014) had severe cataract blindness and the mean age of patients at the time of cataract surgery was 68.4 (Salowi \& Goh, 2016). This shows that the elderly people with severe cataract blindness forms a fair proportion of those benefited from the outreach programs.

The development of a satellite cataract centre in Selayang, a suburban area of Kuala Lumpur, has substantially compliments the outreach program. The satellite centre improves the accessibility to cataract surgery by the impoverished urban and rural population with the total number of cataract surgery done has reached more than 4000 within two years ( 2014 \& 
2015) since its inauguration in 2013 (Salowi \& Goh, 2016). This concept of outreach program and satelite cataract service need to be further expanded throughout the country as addressing the barriers at the primary and specialist care level has markedly improve the provision and utilisation of eye care and cataract surgical services among the needy elderly population.

Cost has always been considered a significant issue as one of the main barriers to cataract surgery among the poor and underprivileged patients. To address this issue, the national intraocular lenses (IOL) bank was developed with an initial grant worth more than RM3 million from the Standard Chartered Foundation (SCF) in partnership with the Ministry of Health Malaysia since 2013. Through this key initiative project of the SCF, and with additional contributions by other non-governmental organisations throughout Malaysia, the poor can acquire free or subsidised IOL required for their cataract surgery. The national IOL bank has since contributed over 4,400 free intraocular lenses required for quality eye care and cataract surgeries for the underprivileged patients across Malaysia (SCF, 2017). So, cost incurred upon patients for surgery including IOL, is still one of the major barriers that need to be seriously addressed in all cataract blindness interventional program.

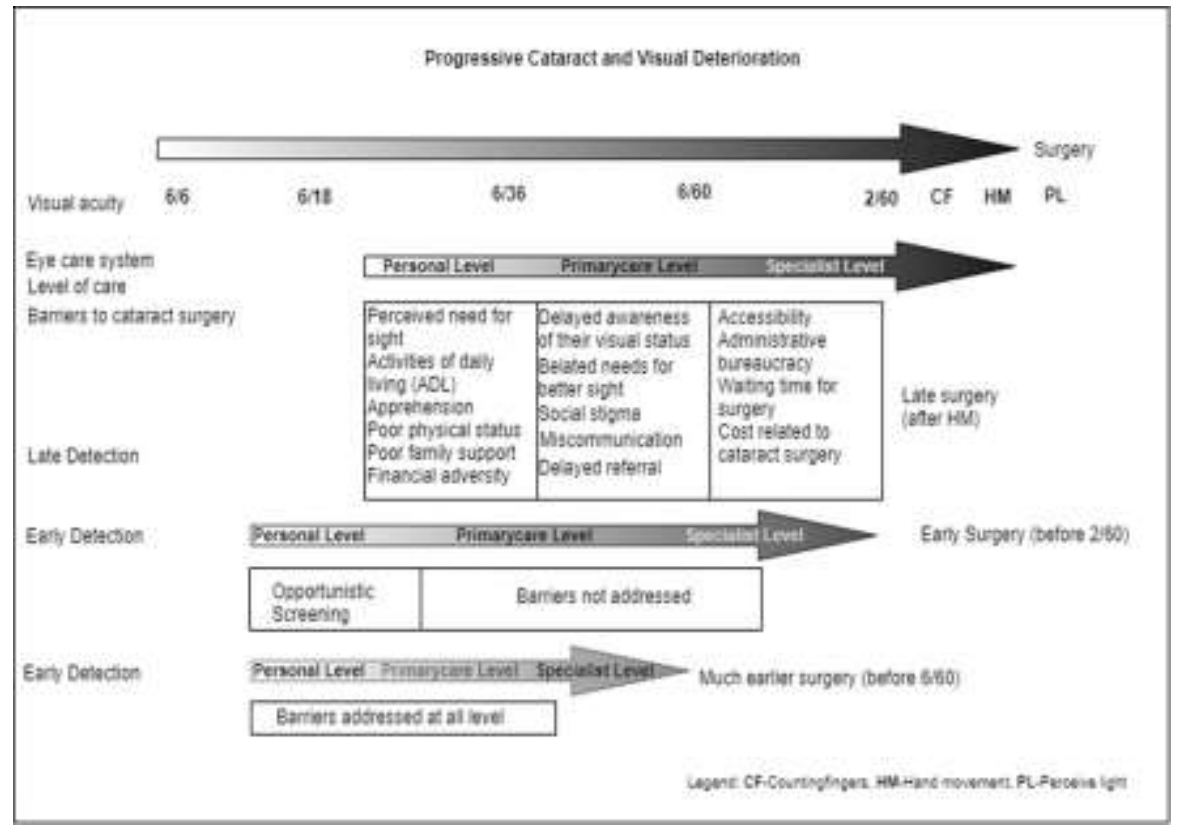

Figure 1: Cataract Surgery Barrier Model in Malaysia

We therefore proposed a Cataract Surgery Barrier (CSB) model as shown in Figure 1 below, which summarises the framework illustrating the presence of barriers at all level of eye care services. This concept has never been described in any of the previous surgical 
care barrier models. The arrows symbolise the state of progressive cataract causing visual deterioration from visual acuity of 6/6 to worse than $3 / 60$ (severe blindness) if not treated by surgery. The proposed CSB model provides the framework for designing and implementing strategic interventional programs to improve cataract detection and its surgical uptake. Addressing the barriers at every level of care could expedite the process for timely uptake of cataract surgery as the only effective way to improve vision, well-being and quality of life in our community.

However, as in any qualitatively designed studies, the limitation of this study includes limited participation and might not truly represent the whole population of Malaysia. Thus, a nationwide population-based survey is duly required for this purpose. As the study was unintentionally more represented by the Malay in rural areas, their perspectives might have limited extrapolation to the multiracial population of Malaysia. A further study to focus on other specific population groups in Malaysia is required to verify the more specific and significant barriers present among them.

\subsection{Conclusion}

The IPA approach employed in this study has successfully identified the barriers to cataract surgery by understanding how patients with severe cataract blindness made sense of their lived experiences during the whole period of their visual deterioration. The barriers are classified at three levels of care ie. at the personal level followed by the primary care and finally the specialist care level. An in-depth interpretation of those who had denied, delayed and agreed to undertake the cataract surgery has allowed us to define the characteristics and level of barriers to cataract detection, the care process and surgery at every level of the health care system. Our proposed CSB model could improve our understanding of how to provide a more inclusive and comprehensive eye care services, as well as how to increase the uptake of early cataract surgery, so as to prevent blindness among patients affected by cataract - in a way that was not well described in any previous health care barrier model. It is currently could be the best available framework to design a more effective interventional strategy for the prevention of cataract blindness program in Malaysia.

\section{Acknowledgement}

There was no external grant obtained for this study. It was fully self-sponsored by all the contributing authors. The authors would like to thank all the study participants and family members for their cooperation and all optometrists who have assisted in identifying the study participants for this study.

\section{References}

Aisyah, A.B., Mariana, M.O., Syahriah, B., \& Mansor, I. (2016). Investigating Rationales of Malaysia Quality of Life and Wellbeing Components and Indicators. Procedia - Social and Behavioural Sciences, 222, 132-42. 
Andersen, R.M. (2008). National health surveys and the behavioural model of health services use. Med Care, 46, 647.

Bourne, R.R.A., Flaxman, S.R., Braithwaite, T., Cicinelli, M.V., Das, A., Jonas, J.B., et al. (2017). Vision Loss Expert Group. Magnitude, temporal trends, and projections of the global prevalence of blindness and distance and near vision impairment: a systematic review and meta-analysis. Lancet Glob Health, 5(9), e888-97.

Carrillo, J.E., Carrillo, V.A., Perez, H.R., Salas-Lopez, D., Natale-Pereira, A., and Byron, A. (2011). Defining and Targeting Health Care Access Barriers. J Health Care Poor Underserved, 22, 562-575

Chew FLM, Salowi MA, Mustari Z, Husni MA, Hussein E, Adnan TH, et al. (2018) Estimates of visual impairment and its causes from the National Eye Survey in Malaysia (NESII). PLoS ONE, 13(6), e0198799.

Dhaliwal, U., \& Gupta, S.K. (2007). Barriers to the uptake of cataract surgery in patients presenting to a hospital. Indian J Ophthalmol, 55(2), 133-6.

Ibrahim, S.A.S. \& Dahlan, A. (2015). Engagement in Occupational Activities and Purpose in Life amongst Older People in the Community and Institutions. Procedia - Social and Behavioural Sciences, 202, 263-72.

Irfan, F.B., Irfan, B.B., \& Spiegel, D.A. (2012). Barriers to accessing surgical care in Pakistan: Healthcare barrier model and quantitative systematic review. J Surg Res, 176, 84-94.

Kovai, V., Krishnaiah, S., Shamanna, B.R., Thomas, R., \& Rao, G.N. (2007). Barriers to accessing eye care services among visually impaired populations in rural Andhra Pradesh, South India. Indian J Ophthalmol, 55(5), 365-71.

Mahesh, C., Suraj, K., Kishor, D., et al. (2013). Morbidity pattern and treatment seeking behaviour of geriatric population in Jamnagar city. J Res Med Den Sci, 1, 12-6.

McIntyre, D., Thiede, M., \& Birch, S. Access as a policy-relevant concept in low- and middle-income countries. Health Econ Policy Law, 4(2), 179.

Mutalib, A.S.A., Dahlan, A., Masuri, M.G., \& Danis, A. (2016) Interdependence among Malay older people who live in the community: An Interpretative Phenomenological Analysis. Procedia - Social and Behavioural Sciences, 234, 90-7.

Nurulain, M.Z., Shahir, A., Asma, H., \& Mutalib, A. (2018) Primary Care Barriers to Cataract Surgery in the Eastern Zone of Peninsular Malaysia: An Interpretative Phenomenological Analysis. Med J Malaysia, 73(2), 67-72.

Obrist, B., Iteba, N., Lengeler, C., et al. (2007). Access to health care in contexts of livelihood insecurity: A framework for analysis and action. PLoS Med, 4, 1584.

Plummer-D'Amato. (2008). Focus Group Methodology Part 1: Consideration for design. Int J Ther Rehabil, 15(2), 69-73.

Salowi, M.A. (2015). National Eye Survey Report 2014. Ophthalmology service: Ministry of Health Malaysia. Kuala Lumpur.

Salowi, M.A., \& Goh, P.P. (2016) Ninth Report of the National Eye Database 2015. Ministry of Health Malaysia. Kuala Lumpur

Smith, J.A. (2016). Interpretative phenomenological analysis: Getting at lived experience. J Posit Psychol, 12(3),12. 
Mutalib, A., et.al. / Journal of ASIAN Behavioural Studies (jABs), 4(13) May / Aug 2019 (p.1-13)

Smith, J.A., Flowers, P., \& Larkin, M. (2009). Interpretative Phenomenological Analysis: Theory, method and research. SAGE Publications Inc.

Standard Chartered Foundation Key Initiatives (2017): Giving the Gift of Sight to underprivileged cataract patients. [Cited Jan 2019]. Available at https://www.sc.com/my/news-media/foundation/support/

Vaidyanathan, K., Limburg, H., Foster, A., \& Pandey, R.M. (1999). Changing trends in barriers to cataract surgery in India. Bull World Health Organ, 77(2), 104-9.

World Health Organization. (2007). Vision 2020 - Global initiative for the elimination of avoidable blindness: action plan 2006-2011. Report of a WHO Working Group. Geneva. 